\title{
Two incisions are better than one
}

\author{
Carl Lewis Backer, MD
}

\author{
From the Division Head, Cardiovascular-Thoracic Surgery, Ann \& Robert H. Lurie Children's Hospital of \\ Chicago, and A.C. Buehler Professor of Surgery, Northwestern University Feinberg School of Medicine, \\ Chicago, Ill. \\ Disclosures: Dr Backer is a consultant for W.L. Gore \& Associates, Inc, Flagstaff, Ariz. \\ Received for publication Nov 8, 2017; accepted for publication Nov 9, 2017; available ahead of print Dec 14, \\ 2017. \\ Address for reprints: Carl Lewis Backer, MD, Cardiovascular-Thoracic Surgery, Ann \& Robert H. Lurie Chil- \\ dren's Hospital of Chicago, 225 E Chicago Ave, mc 22, Chicago, IL 60611 (E-mail: cbacker@ \\ luriechildrens.org). \\ J Thorac Cardiovasc Surg 2018;155:2103 \\ $0022-5223 / \$ 36.00$ \\ Copyright (C) 2017 by The American Association for Thoracic Surgery \\ https://doi.org/10.1016/j.jtcvs.2017.11.017
}

Dr Hang and colleagues ${ }^{1}$ from the Mayo Clinic have presented for us an extremely interesting group of patients with complex hypertrophic cardiomyopathy. These patients have both subaortic hypertrophic cardiomyopathy and either midventricular hypertrophy or apical hypertrophy leading to left ventricular cavity obliteration and diastolic dysfunction. These patients were treated by a combination of transaortic and transapical septal myectomy -2 incisions to access the lesion. The results were excellent, with short crossclamp and cardioplegia times, low postoperative residual gradients, and excellent 1-year survival. There were no complications related to the use of 2 incisions. The authors' experience with this group of complex patients is another major contribution to their already-extensive contributions regarding patients with hypertrophic cardiomyopathy.

Recently, a patient with complex hypertrophic cardiomyopathy was referred to us for heart transplantation. There was massive hypertrophy of the entire septum $(5 \mathrm{~cm}$ maximum width) and left ventricular cavity obliteration. Based on the authors' previous manuscripts and after consultation with Dr Dearani, we elected to proceed with the operation described by Dr Hang. We performed a combined transaortic and transapical approach. The amount of muscle resected was astounding_-30 grams! Importantly, the postoperative echocardiogram showed a normal-sized left ventricular cavity with excellent ventricular function. This patient did not require a cardiac transplant.

In addition to the excellent hemodynamic outcomes, the use of this strategy in the Mayo series was associated with a very low incidence of heart block and iatrogenic ventricular septal defect. Only 1 patient had an iatrogenic ventricular septal defect (early in the series), and only 3 patients had postoperative third-degree heart block. The 2-incision approach allows excellent visualization and accurate septal resection. Another point of interest for me is that comfort with this operation is facilitated by experience with placing a ventricular assist device in the left ventricular apex and resecting muscle for left ventricular assist device placement. ablation.

\section{Reference} 2096-102.

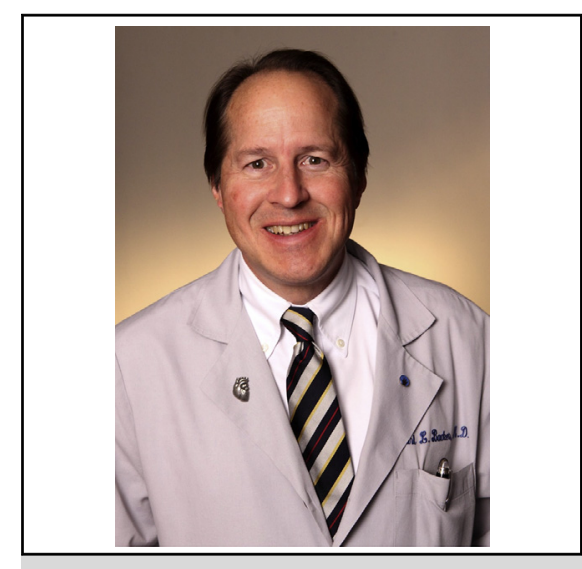

Carl Lewis Backer, MD

Central Message

The combination of transaortic and transapical resection of the septum can be an extremely successful procedure for properly selected patients. Although a daunting operation, results are excellent.

See Article page 2096.

Experience with tipping the heart up and opening the apex of the left ventricle with 1 operation makes one more comfortable with that approach for another operation. Finally, these excellent results appear to show that this is a safe and durable treatment and should be considered carefully compared with the use of transcatheter alcohol septal

It is the sharing of data such as these that allows other centers to adapt new techniques to successfully treat complex patients. This is a magnanimous reflection of our field's general principle to put the needs of the patient first and to teach others how we do complex surgical procedures, disseminating the surgical techniques for all to see. We greatly appreciate the authors presenting this information and demonstrating how to have a successful outcome in a group of patients in whom transaortic resection is simply not enough. The use of the 2 incisions, although a daunting operation, actually makes this operation easier and more importantly successful.

1. Hang D, Schaff HV, Ommen SR, Dearani JA, Nishimura RA. Combined transaortic and transapical approach to septal myectomy in patients with complex hypertrophic cardiomyopathy. J Thorac Cardiovasc Surg. 2018;155: 